\title{
Fundo de Garantia Salarial - O prazo para requerer o pagamento dos créditos laborais e a sua (in)compatibilidade com o Direito Comunitário e a Constituição ${ }^{33}$
}

\section{Salary Guarantee Fund - The time-limit for lodging applications for payment of outstanding salary and its (in)compatibility with the Community Law and the Constitution}

Inês Castelo Branco ${ }^{1}$;

${ }^{1}$ E-mail: icbranco@outlook.pt

Doutoranda na Faculdade de Direito

da Universidade de Coimbra |

Advogada na CRBA -

Sociedade de Advogados, RL
Resumo: O NRFGS passou a prever que o FGS só assegura o pagamento dos créditos laborais quando o pagamento lhe seja requerido até um ano a partir do dia seguinte àquele em que cessou o contrato de trabalho (art. ${ }^{\circ} 2 .^{\circ}$, n. $^{\circ} 8$ ). Esta alteração consubstancia uma alteração do prazo anterior, previsto no art. ${ }^{\circ}$ 319. ${ }^{\circ}$, n. $^{\circ} 3$ da RCT, porque o atual deixou de estar indexado ao prazo de prescrição dos créditos laborais, e, consequentemente, deixou de poder aproveitar as causas de interrupção deste. Os nossos tribunais têm sido chamados a dirimir litígios relacionados com a alteração deste prazo, mas, salvo o devido respeito, de maneira não totalmente satisfatória. A nosso ver, a referida norma não é compatível com a Diretiva 2008/94/CE, por violação do princípio da efetividade, nem com o art. $^{\circ} 59 .^{\circ}$, n. ${ }^{\circ}$ s 2 e 3 da CRP.

Palavras-chave: Fundo de Garantia Salarial; trabalhadores; insolvência do empregador.

Abstract: The new legal regime of the Salary Guarantee Fund stipulates that it only guarantees the payment of outsanding salary when it is required until one year from the day after of the termination of the labour contract (art. ${ }^{o}$ $\left.2 .^{o},{ }^{o}{ }^{\circ} 8\right)$. There was a modification of the previous time-limit (art. ${ }^{o} 319 .^{o},{ }^{o} .^{o}$ 3 of the Regulamentation of the Labour Code), because the current one is no longer related to the prescription time-limit of outstanding salary claims and, consequently, it is no longer possible to take advantage of interrupting causes. There are already some Court's decisions, however, with all due respect, not totally satisfactory. In our opinion, that art. ${ }^{\circ} 2 .^{\circ},{ }^{\circ}{ }^{o} 8$ do not respect the Directive 2008/94/CE, disregarding the principle of effectiveness, and the art. ${ }^{\circ} 59 .^{\circ}, n .^{\circ}$ s and 3 of the Constitution.

Keywords: Salary Guarantee Fund; workers; insolvency of the employer. 


\section{pontěditora}

\section{Introdução - os termos do problema}

Após uma espera de mais de 6 anos, através do DL n. ${ }^{\circ}$ 59/2015, de 21 de abril, que aprovou o NRFGS, concretizou-se a revogação do anterior regime jurídico do FGS, que se encontrava dispersamente previsto no CT 2003 (art. ${ }^{\circ} 380 .^{\circ}$ ), na RCT (arts. 316. ${ }^{\circ}$ a 326. ${ }^{\circ}$ ) e no DL n. ${ }^{o}$ 139/2001, de 24 de abril.

Dessa forma, a partir de 4 de maio de 2015, data da sua entrada em vigor ( art. $^{\circ}$ 5. $^{\circ}$ ), a legislação específica a que se refere o art. $^{\circ} 336^{\circ}$ do CT passou a ser o NRFGS.

Neste artigo iremos analisar, somente, um dos aspetos do NRFGS - o prazo do trabalhador para requerer ao FGS o pagamento dos créditos emergentes do contrato de trabalho ou da sua violação ou cessação -, um dos aspetos, adiantamos já, que sofreu alteração.

O FGS assegura, aos trabalhadores, o pagamento dos seus créditos emergentes de contrato de trabalho, ou da sua violação ou cessação, que não possam ser pagos pelo empregador por motivo de insolvência ou de situação económica difícil (art. ${ }^{\circ} 380 .^{\circ}$ do CT 2003 e art. $^{\circ} 336 .^{\circ}$ do CT).

No regime anterior, esse pagamento tinha de ser requerido (o mesmo é dizer, o direito do trabalhador a ser pago pelo FGS tinha de ser exercido) até três meses antes da prescrição dos créditos laborais cujo pagamento estava a ser reclamado ao FGS (art. ${ }^{\circ} 319 .^{\circ}$, n. $^{\circ} 3$ da RCT). Esta formulação obrigava-nos, então, a verificar o prazo de prescrição dos créditos laborais previsto no CT 2003, a qual ocorria um ano a partir do dia seguinte àquele em que cessou o contrato de trabalho $\left(\operatorname{art}^{\circ} 381 .^{\circ}\right.$, n. $^{\circ} 1$ ).

Por seu turno, o art. $^{\circ} 2 .^{\circ}$, n. $^{\circ} 8$ do NRFGS estabelece o prazo de um ano a partir do dia seguinte àquele em que cessou o contrato de trabalho.

Comparando a literalidade das duas normas, verificamos que, se anteriormente, o prazo para o exercício do direito estava indexado (Domingos, 2009, pp. 263 e 264) a outro prazo, o da prescrição dos créditos laborais, agora não está.

Essa diferença é, a nosso ver, essencial, dado que, anteriormente, como o prazo do trabalhador para requerer o pagamento ao FGS estava indexado a um prazo de prescrição, tínhamos de ter em atenção as situações de interrupção e suspensão desse prazo, previstas no CC, em particular, nos artigos $323 .^{\circ}$ e $327 .^{\circ}$.

Desse modo, e na verdade, "o prazo de reclamação desencade[ava-se] em momentos diferentes, variando de caso para caso, em função do momento em que cessou a relação laboral e em função da ocorrência ou não de suspensão ou interrupção do prazo de prescrição, nos termos dos artigos 


\section{pontěditora}

318. ${ }^{\circ}$ e seguintes do CC, pelo que, na verdade, este prazo de três meses pod[ia] ter a montante um período de tempo bastante alargado" (Domingos, 2009, pp. 263 e 264). No mesmo sentido, ia a jurisprudência, designadamente, o Ac. doSTA, de 17/12/2014, processo n. ${ }^{\circ}$ 0632/12, relator Carlos Carvalho, disponível na base de dados acessível em www.dgsi.pt.

Por exemplo, a reclamação de créditos no próprio processo de insolvência interromperia esse prazo, o qual não começaria a correr enquanto não transitasse em julgado a decisão que pusesse termo ao processo (que, no caso, seria a sentença de verificação e graduação de créditos).

Desse modo, salvo o devido respeito, não é inteiramente rigorosa a conclusão que o pagamento teria de ser requerido antes de terem passado nove meses do fim do contrato de trabalho (Abrantes, 2009, p. 412). Por via de regra, sim, mas era preciso ter em conta as situações de interrupção e suspensão.

E agora, com o NRFGS?

Deixando de haver essa indexação, a única data relevante para a contagem do prazo para o exercício do direito de reclamar o pagamento dos créditos laborais ao FGS é a data em que cessou o contrato de trabalho do trabalhador.

Ademais, se, anteriormente, ao prazo de prescrição de um ano e um dia teríamos de descontar três meses, agora temos um prazo contínuo de um ano a partir do dia seguinte àquele em que cessou o contrato de trabalho.

E, assim, tem entendido e decidido o FGS.

Sobre este ponto, o nosso legislador, no preâmbulo do DL n. ${ }^{o}$ 59/2015, de 21 de abril, assume a existência de uma alteração, quando afirma o seguinte: "Promovendo uma lógica de estabilidade temporal e de segurança jurídica manteve-se no novo regime a regra de que o FGS assegura o pagamento dos créditos que se tenham vencido nos seis meses anteriores à propositura da ação de insolvência ou à apresentação do requerimento do PER ou do procedimento extrajudicial de recuperação de empresas, atualmente o SIREVE, passando-se agora, no entanto, a prever que o pagamento dos créditos requeridos é assegurado até um ano a partir do dia seguinte àquele em que cessou o contrato de trabalho".

Esta alteração surgiu logo na versão inicial do projeto de DL sobre o FGS apresentado, pelo Governo, aos seus parceiros sociais em sede de Concertação Social, na reunião plenária de 6 de outubro de 2014 , sendo que, das atas relativas às reuniões plenárias em que se discutiu este assunto (as atas n. ${ }^{\circ} 7 / 2014$, da reunião plenária de 09.07.2014, n. ${ }^{\circ}$ 9/2014, da reunião plenária de 6/10/2014 e n. ${ }^{\circ}$ 10/2014, de 2/12/2014) não consta qualquer justificação para esta mudança, nem que esta mudança tivesse sido, sequer, contestada. 


\section{pontěditora}

Assim, esta alteração vingou até à versão final do diploma aqui em análise.

Por seu turno, a doutrina tem ido no sentido de que essa alteração correspondeu a um aumento em três meses do prazo anterior (Abrantes, 2015, p. 412 e Costeira, 2017, p. 144).

Sucede que, na prática, tem-se verificado que essa alteração, em alguns casos, tem correspondido a uma redução do prazo anterior.

E, igualmente, porque a este novo prazo ficaram sujeitos os requerimentos apresentados após o dia 4 de maio de 2015 (art. $^{\circ}$ 3. $^{\circ}$, n. $^{\circ} 1$ do DL n. ${ }^{\circ}$ 59/2015, de 21 de abril), tem-se verificado que esta alteração tem afetado contratos de trabalho que cessaram antes da entrada em vigor do NRFGS, quando os requerimentos foram apresentados após aquela data.

E, por isso, os nossos tribunais já têm sido chamados a dirimir litígios relacionados com a aplicação do $\operatorname{art}^{\circ}{ }^{2} .^{\circ}$, n. $^{\circ} 8$ do NRFGS, tendo sido, até à data em que escrevemos, publicados, na base de dados disponível em www.dgsi.pt, seis acórdãos de tribunais superiores, que aqui se enunciam, do mais antigo para o mais recente, tendo em conta a data do acórdão:

1) Ac. do TCA-Norte, de 28/04/2017, processo n. ${ }^{\circ}$ 00840/16.9BEPRT, relator Rogério Paulo da Costa Martins;

2) Ac. do TCA-Sul, de 01/06/2017, processo n. ${ }^{\circ}$ 3462/15.8BESNT, relator Helena Canelas;

3) Ac. do TCA-Norte, de 14/07/2017, processo n. ${ }^{\circ}$ 00698/16.8BEPNF, relator Rogério Paulo da Costa Martins;

4) Ac. do TCA-Norte, de 22/09/2017, processo n. ${ }^{\circ}$ 02277/16.0BEPRT, relator Alexandra Alendouro;

5) Ac. do TCA-Norte, de 4/10/2017, processo n. ${ }^{\circ}$ 00885/16.9BEPRT, relator Luís Migueis Garcia;

6) Ac. do TCA-Sul, de 10/05/2018, processo n. ${ }^{\circ}$ 690/16.2BEALM, relator Helena Canelas.

Damos, ainda, nota de que foi apresentado, a 5 de dezembro de 2016, pelo TAF de Viseu, junto do TJ, um pedido de decisão prejudicial (processo C-627/16, João Ventura Ramos/Fundo de Garantia Salarial), em que foram feitas as seguintes questões prejudiciais:

"Um prazo de caducidade aplicável ao pedido de pagamento pela instituição de garantia de créditos salariais em dívida é mais favorável aos trabalhadores assalariados, na aceção do artigo $11^{\circ}$ da Diretiva 2008/94/CE, do Parlamento Europeu e do Conselho, de 22 de outubro de 2008, relativa à proteção dos trabalhadores assalariados em caso de insolvência do empregador, quando só é assegurado o pagamento de tais créditos quando o pagamento seja requerido à 


\section{pontěditora}

instituição de garantia até um ano a partir do dia seguinte àquele em que cessou o contrato de trabalho ou se se contasse a partir da data da propositura da ação de insolvência, considerando que a instituição de garantia só assegura o pagamento dos créditos do trabalhador que se tenham vencido nos seis meses anteriores à sua propositura?

Se um trabalhador tiver deixado passar o prazo por razões de que não seja responsável, devem as legislações dos Estados-Membros, ao abrigo do disposto no artigo $11^{\circ}$ da Diretiva 2008/94/CE, do Parlamento Europeu e do Conselho, de 22 de outubro de 2008, prever um prazo adicional para a apresentação do seu pedido, desde que o trabalhador demonstre que não é responsável pela inobservância do prazo de caducidade?”.

Contudo, estas questões prejudiciais ficaram por responder (Serra, 2017, p. 167) porque, a 23 de março de 2017, o TJ cancelou o processo por ter deixado de haver um litígio pendente no tribunal português.

Voltando à jurisprudência nacional, da leitura dos seis acórdãos concluímos que, em todos, os contratos de trabalho cessaram antes da entrada em vigor do NRFGS (e quando nem sequer havia sido apresentado o referido projeto sobre a alteração do regime jurídico do FGS), mas todos foram entregues já na vigência do NRFGS:

1) Cessação do contrato de trabalho dos trabalhadores: 19/09/2013 e 05/09/2013; ação laboral, em que houve reconhecimento dos créditos laborais; início do processo de insolvência relevante para o FGS: 04/11/2014; entrega dos requerimentos: 14/07/2015 e a $15 / 07 / 2015$.

2) Cessação do contrato de trabalho, por revogação, com pagamento prestacional de compensação pecuniária de natureza global: 06/06/2013; ação laboral:10/02/2014, com trânsito em julgado a 28/04/2015; início do processo de insolvência: 26/03/2015; entrega do requerimento: 12/06/2015.

3) Cessação do contrato de trabalho: 13/11/2013 ou 18/02/2014 ${ }^{34}$; início do processo de insolvência: 26/12/2013; verifcação ulterior de créditos: 03.07.2014; entrega do requerimento: 30/10/2015.

4) Cessação do contrato de trabalho: 30/12/2013; início do PER: 15/02/2013; entrega do requerimento: 18/08/2015.

\footnotetext{
${ }^{34}$ Cremos que haverá algum lapso nos factos provados, porque surgem estas duas datas como a da cessação do contrato de trabalho.
} 


\section{pontěditora}

5) Cessação do contrato de trabalho: 07/05/2014; ação laboral:04/12/2014, com trânsito em julgado a 10/02/2015; entrega do requerimento: 03/06/2015.

6) Cessação do contrato de trabalho, por revogação, com pagamento prestacional de compensação pecuniária de natureza global: 30/11/2012; início PER: 14/08/2013, com despacho de homologação em 11/04/2014; declaração de insolvência (não é disponibilizada a data de início do processo): 08/06/2015; entrega do requerimento: $24 / 08 / 2015$.

O FGS indeferiu os requerimentos dos trabalhadores, por não terem sido apresentados no prazo de 1 ano a partir do dia seguinte àquele em que cessou o contrato de trabalho, nos termos do art. $^{\circ}$ 2. $^{\circ}$, no 8 do NRFGS (cfr. todos os Acs.), não estando em causa qualquer prazo de prescrição, mas sim de caducidade (cfr. o Ac. n. ${ }^{\circ}$ 2).

Foram duas as teses assumidas, com consequências opostas.

Por um lado, temos os que consideraram que, se, do caso concreto, o prazo, de caducidade, previsto no art. ${ }^{\circ} 2 .^{\circ}$, n. $^{\circ} 8$ do NRFGS, se mostrar mais curto do que o prazo previsto no art. ${ }^{o}$ 319. ${ }^{\circ}$, n. 3 da RCT, impor-se-á, então, o recurso ao art. $^{\circ} 297 .^{\circ}$, n. $^{\circ} 1$ do CC, e, em consequência, o prazo de um ano só começará a contar a partir da data da entrada em vigor do NRFGS, a 4 de maio de 2015 (cfr. os Acs. n. ${ }^{\circ}$ s 1, 4, 5 e 6). Se assim for, será tempestivo o exercício do direito dos trabalhadores.

Por outro lado, temos os que consideraram que o novo prazo é um prazo de caducidade, que, por isso, nos termos do art. $328 .^{\circ}$ do $\mathrm{CC}$, não se suspende ou interrompe, estando expressamente fixado na letra da lei o início da contagem desse prazo, o dia seguinte àquele em que cessou o contrato de trabalho (cfr. os Acs. n. ${ }^{\circ}$ s $2^{35}$ e 3). Foi, por isso, considerado intempestivo o exercício do direito dos trabalhadores.

Quanto ao primeiro grupo, para chegarem a tal decisão, começaram por afirmar que o prazo estabelecido no art. $^{\circ} 2 .^{\circ},{ }^{\circ}{ }^{\circ} 8$ do NRFGS é um prazo de caducidade e que esse prazo era o aplicável àqueles trabalhadores, porque os requerimentos foram apresentados após a entrada em vigor do DL n. ${ }^{\circ} 59 / 2015$, de 21 de abril.

\footnotetext{
${ }^{35}$ Regista-se a mudança de posição da relatora e da adjunta deste Ac. que, mais tarde, subscreveram o Ac. n. ${ }^{\circ} 6$.
} 


\section{pontěditora}

Contudo, em sintonia com o princípio do Estado de Direito e da tutela da confiança, subjacentes ao princípio que as leis se aplicam para futuro, nos termos do art. ${ }^{\circ} 12 .^{\circ}$ do $\mathrm{CC}$, não pode, sem mais, ser aplicado este novo prazo (cfr., em particular, o Ac. n. ${ }^{\circ} 6$ ).

Desse modo, há que ter em atenção o art. $.^{\circ} 297 .^{\circ},{ }^{\circ} .^{1}$ do CC, de acordo com o qual se a lei estabelecer um prazo mais curto do que o fixado na lei anterior é também aplicável aos prazos que já estiverem em curso, mas o prazo só se conta a partir da entrada em vigor da nova lei. As instâncias superiores averiguaram, então, se o prazo anterior ainda estava em curso aquando da entrada em vigor do NRFGS e, em caso afirmativo, se, na situação concreta, o novo prazo se mostrava mais curto que o antigo, tendo em conta que este se encontrava indexado ao prazo de prescrição dos créditos laborais, o que implicava considerar as causas de interrupção e suspensão, e que novo prazo voltaria a correr.

Nos Acs. n. ${ }^{\circ}$ s 1, 5 e 6, foi considerado que, ao abrigo do art. ${ }^{\circ} 323 .^{\circ}$, n. $^{\circ} 1$ do $\mathrm{CC}$, houve interrupção do prazo de um ano de prescrição com a instauração da ação laboral (cfr. os Acs. n. ${ }^{\circ} 1$ e 5) e com a reclamação de créditos no PER e no processo de insolvência (cfr. o Ac. n. ${ }^{\circ}$ 6), que inutilizaram o prazo entretanto decorrido (art. ${ }^{\circ} 326 .^{\circ}$, n. $^{\circ} 1$ do CC), e que começou a correr um novo prazo após transitar em julgado a decisão judicial que pôs termo ao litígio (arts. 326. ${ }^{\circ}$, n..$^{\circ} 1$ e $327 .^{\circ},{ }^{\circ}{ }^{\circ} 1$ do CC), o prazo ordinário, de 20 anos, porque houve sentença a reconhecer os créditos laborais (arts. $311 .^{\circ}$, n. $^{\circ} 1$ e $309 .^{\circ}$ do CC),

Consequentemente, na prática, para aqueles casos, a lei nova estabelecia um prazo mais curto, pelo que era aplicável o art. ${ }^{\circ} 297 .^{\circ}$, n. $^{\circ} 1$ do CC e, assim, o prazo de um ano de caducidade só começaria a contar a partir de 4 de maio de 2015 e o exercício do direito caducaria a 4 de maio de 2016. Por isso, os requerimentos foram entregues tempestivamente.

No Ac. n. ${ }^{\circ}$, o tribunal considerou intempestivo o exercício do direito do trabalhador porque entendeu que "não resulta da factualidade assente qualquer causa de interrupção da prescrição dos créditos laborais requeridos pelo Recorrente, de molde a permitir ao tribunal formar convicção no sentido do novo prazo se mostrar, em concreto, mais curto do que o previsto na lei antiga. Antes resulta que o prazo para a apresentação do requerimento ao FGS já se encontrava esgotado, aquando da entrada em vigor da nova lei, seja de acordo com a antiga seja com aquela, não cabendo assim chamar à colação o disposto no artigo 297. ${ }^{\circ}$ do CC que regula situações em que os prazos se iniciem ou já se encontre em curso à data da entrada em vigor da lei nova".

Quanto ao segundo grupo, aplicaram o regime jurídico da caducidade, nomedamente, que os prazos de caducidade não se suspendem nem se interrompem ( $\operatorname{rrt}^{\circ}{ }^{\circ} 328 .^{\circ}$ do CC), que a lei 


\section{pontěditora}

pode fixar a data em que começa a correr esses prazos (art. $329 .^{\circ}$ do CC) e que só impede a caducidade a prática do ato dentro do prazo legal ( $\operatorname{art}^{\circ} 331 .^{\circ},{ }^{\circ} .^{\circ} 1$ do CC). Por isso, concluíram que a instauração da ação judicial para condenação da entidade patronal no pagamento dos seus créditos laborais (cfr. o Ac. n. ${ }^{\circ}$ 2), ou a instauração e pendência do processo de insolvência ou de graduação de créditos (cfr. o Ac. n. ${ }^{\circ}$ 3), não interrompeu ou suspendeu o prazo de um ano previsto no artigo 2..$^{\circ}$. ${ }^{\circ} 8$ do NRFGS.

De particular, no Ac. n. ${ }^{\circ} 2$ foi, igualmente, defendido que esta era uma interpretação conforme com a Diretiva 2008/94/CE, com a jurisprudência comunitária (Ac. do TJ, de 28.11.2013, processo C-309/12, e o Despacho, de 10.04.2014, processo n. ${ }^{\circ} \mathrm{C}-511 / 12$ ) e que não havia qualquer infração aos arts. $59 .^{\circ}$, n. $^{\circ} 1$, a) e $13 .^{\circ}$ da CRP.

E, relativamente ao Ac. n. ${ }^{\circ}$ 3, segundo nos parece, foi entendido que esta posição respeitaria a finalidade social da Diretiva, "que justifica que sejam adoptados limites à sua intervenção, não só limites temporais que decorrem do enquadramento comunitário que lhe está subjacente (Directiva 80/987/CE, de 20.10), como também, limites às importâncias pagas”.

Aparte da dissonância exposta, de comum, todos os Acs. afirmam que tanto o anterior prazo, como o atual, são prazos de caducidade, de acordo com o art. $.^{\circ} 298 .^{\circ}$, n. $^{\circ} 1$ do CC, e que, com o NRFGS, houve uma alteração do prazo. Pelo que, a alteração do prazo não modificou a sua natureza (cfr., em particular, os Acs. n. ${ }^{\circ}$ s 1 e 6).

Ora, ainda que, entre os dois grupos, nos pareça mais acertado o decidido pelo primeiro, salvo o devido respeito, nem um, nem outro dão uma resposta cabalmente satisfatória à questão, porque, a nosso ver, não foi tida em devida conta o contexto normativo e jurisprudencial, nacional e comunitário.

\section{Apreciação crítica}

\subsection{Contextualização}

No seio comunitário, a proteção dos créditos dos trabalhadores é assegurada através de instituições de garantia.

A Diretiva n. ${ }^{\circ}$ 80/987/CEE, do Conselho, de 20 de outubro de 1980, relativa à aproximação das legislações dos Estados-membros respeitantes à proteção dos trabalhadores assalariados em caso de insolvência do empregador, determinou, pela primeira vez na Comunidade Europeia, que os Estados-membros tomariam as medidas necessárias para que fosse assegurado por 


\section{pontěditora}

instituições de garantia o pagamento dos créditos dos trabalhadores quando os empregadores se encontrassem em estado de insolvência (arts. $1 .^{\circ}$ e $3 .^{\circ}$ ).

Esta Diretiva enquadrou-se nos desígnios da Comunidade Europeia promover o regular funcionamento do mercado comum e a melhoria das condições de vida e de trabalho, através da harmonização das legislações nacionais (arts. $1000^{\circ}$ e $117 .^{\circ}$ do Tratado que instituiu a Comunidade Económica Europeia, de 1957). Tinha, portanto, uma finalidade social (art. ${ }^{\circ} 4 .^{\circ}$, n. ${ }^{\circ} 3$ da Diretiva).

Entretanto, a Diretiva 80/987/CEE foi alterada, nomeadamente e substancialmente, pela Diretiva n. ${ }^{\circ}$ 2002/74/CE, do Parlamento Europeu e do Conselho, de 23 de Setembro, pelo que se procedeu à codificação daquela, incorporando, na versão original, as alterações que, entretanto, a mesma sofreu, o que foi feito através da Diretiva n. ${ }^{\circ}$ 2008/94/CE, do Parlamento Europeu e do Conselho, de 22 de Outubro de 2008, relativa à proteção dos trabalhadores assalariados em caso de insolvência do empregador (versão codificada).

A nível nacional, com inspiração na Diretiva 80/987/CEE (Domingos, 2009, p. 251), o nosso primeiro diploma a prever um sistema de garantia salarial foi o DL n. ${ }^{\circ} 50 / 85$, de 27 de fevereiro, regulamentado pelo Despacho Normativo n. ${ }^{\circ}$ 90/85, de 20 de setembro. À altura, foi já estabelecido um prazo para a apresentação, pelo trabalhador, do requerimento para pagamento dos créditos emergentes do contrato de trabalho, no caso, trinta dias contados a partir da data da cessação do contrato de trabalho decorrente da extinção, falência ou insolvência da entidade empregadora (ponto IV n. $^{\circ} 2$ do Despacho Normativo n. ${ }^{\circ}$ 90/85, de 20 de setembro).

Seguiu-se o DL n..$^{\circ}$ 219/99, de 15 de junho, o qual instituiu o FGS (art. ${ }^{\circ} 1 .^{\circ}$ ), e compatibilizou a nossa lei com a Diretiva 80/987/CEE (cfr., nomeadamente, o preâmbulo do diploma).

Na sua versão original, não era previsto um prazo para a entrega do requerimento de pagamento dos créditos pelo FGS, mas acabou por sê-lo, através do DL n. ${ }^{\circ}$ 139/2001, de 24 de abril.

Este diploma aditou um n. 2 ao art. $^{\circ} 7 .^{\circ}$ do DL n. ${ }^{\circ} 219 / 99$, de 15 de junho, com a seguinte redação: "[R]elativamente a créditos referentes a contratos de trabalho extintos e caso o seu titular não interrompa, por qualquer motivo, a respectiva prescrição, o requerimento referido no número anterior deve ser apresentado no prazo de nove meses a contar do início da contagem do prazo prescricional”.

Esse aditamento, segundo consta do preâmbulo do DL n. ${ }^{\circ}$ 139/2001, de 24 de abril, teve em vista "permitir que o Fundo, perante um requerimento de pagamento de créditos relativos a contratos de trabalho já extintos, tenha tempo de desenvolver as diligências necessárias à respectiva recuperação antes da prescrição dos referidos créditos". Assim, o FGS disporia "de 


\section{pontěditora}

um prazo razoável (pelo menos 3 meses) para averiguação da existência e para a recuperação dos créditos antes da respectiva prescrição" (Pires, 2015, p. 265).

No âmbito do CT 2003 e da RCT, tendo em mente o que já apontámos, a redação mudou (art.o 319. ${ }^{\circ}$, n. $^{\circ} 3$ da RCT), mas o sentido normativo manteve-se.

E, por último, atualmente, temos o art. $^{\circ} 2 .^{\circ}$, n. $^{\circ} 8$, do DL n. ${ }^{\circ}$ 59/2015, de 21 de abril. Portanto, como se verifica, o nosso FGS tem origem no direito comunitário.

Assim, fruto dessa origem, "esta figura deverá ser construída e interpretada nesse quadro" (Monteiro, 2016, p. 149), “o que significa que a interpretação dos normativos nacionais haverá de ser feita em conformidade (interpretação conforme)" (cfr. o Ac. n. $\left.{ }^{\circ} 2\right)$.

Essa interpretação conforme resulta, aliás, do $\operatorname{art}^{\circ}{ }^{\circ} .^{\circ}$, n. $^{\circ} 4$ da CRP.

Quanto ao nosso objeto de análise, verificamos que, nem a Diretiva 80/987/CEE, na sua versão original ou com as subsequentes alterações, nem a Diretiva 2008/94/CE estabelecem qualquer prazo para os trabalhadores acionarem o FGS (Domingos, 2009, p. 251).

Perante esta omissão, colocou-se, perante o TJ, a questão de saber se era compatível com a Diretiva (no caso, a Diretiva 80/987/CE) a previsão, por parte dos Estados-membros, de um prazo para os trabalhadores reclamarem o pagamento dos seus créditos junto das instituições de garantia, o qual, se não fosse cumprido, precludiria o direito.

Estamos a referir-nos ao Ac. de 18.09.2003, processo n. ${ }^{\circ}$ C-125/01, Peter Pflücke contra o Bundesanstalt für Arbeit ${ }^{36}$. Peter Pflücke trabalhou numa empresa alemã, até à sua demissão, que produziu efeitos em 30/06/1997, sendo que a empresa lhe ficou a dever o salário desse mês. Entretanto, esta foi objeto de um processo de falência, aberto a 02/01/1998. Segundo o direito alemão, o trabalhador, para obter o pagamento do seu crédito pela instituição de garantia competente, o Bundesanstalt, teria de ter feito o pedido no prazo de dois meses a partir de 02/01/1998, ou seja, entre 03/01/1998 e 02/03/1998. O que não fez.

O TJ retirou do facto de a Diretiva não prever qualquer limitação quanto à possibilidade de os Estados-membros estabelecerem um prazo de caducidade, que estes são, em princípio, livres de o fixar. Por outro lado, assim o justifica o bom funcionamento da instituição de garantia. $\mathrm{Na}$ condição, todavia, de serem respeitados os princípios gerais do direito comunitário.

Assim, o TJ declarou que a Diretiva não se opunha, "na condição de que esse prazo não seja menos favorável do que os prazos relativos a pedidos similares de natureza interna (princípio

${ }^{36}$ Disponível, nomeadamente, através da url https://curia.europa.eu/jcms/jcms/j_6/pt/. 


\section{pontěditora}

da equivalência) e não seja adoptado de modo a tornar na prática impossível o exercício dos direitos reconhecidos pela ordem jurídica comunitária (princípio da efectividade)", sendo que o "órgão jurisdicional nacional deve, se considerar que a disposição nacional que estabelece o prazo de caducidade não está em conformidade com as exigências do direito comunitário e que, além disso, nenhuma interpretação conforme dessa disposição é possível, recusar aplicá-la". Este entendimento voltou a ser seguido pelo TJ no Ac. de 16.07.2009, processo n. ${ }^{\circ}$ C-69/08, Raffaelo Visciano contra Istituto nazionale della previdenza sociale.

Pelo que se impõe a pergunta: o prazo previsto no art. ${ }^{\circ} 2 .^{\circ},{ }^{\circ} .^{\circ} 8$ do NRFGS respeita o princípio da equivalência e/ou o princípio da efetividade?

Sem prescindir, impõe-se, também, outra pergunta: será constitucional?

Ainda ao abrigo do DL n. ${ }^{\circ}$ 50/85, de 27 de fevereiro, se defendia que a ampliação das atribuições do sistema de garantia salarial era juridicamente defensável porque com tal sistema o Estado cumpria a sua expressa incumbência constitucional de assegurar a retribuição a que os trabalhadores têm direito, nos termos do art. $^{\circ}$ 59..$^{\circ}$, n. 2 da CRP (Amado, 1994, p. 164).

Mais tarde, na revisão constitucional de 1997, foi acrescentada, no novo n. ${ }^{\circ}$ 3, a imposição constitucional dos salários gozarem de garantias especiais, nos termos da lei (Canotilho e Moreira, 2014, p. 777).

Com respaldo constitucional desde 1997, a verdade é que, desde que foi instituído no nosso país um sistema de garantia salarial, que os créditos dos trabalhadores passaram a gozar de uma garantia especial, uma espécie de garantia pessoal, em que o Estado funcionaria como um fiador "ope legis" da obrigação retributiva (Amado, 1994, p. 162). Contudo, o nosso legislador laboral só o assumiu expressamente a partir do CT 2003, inserindo o art. $^{\circ} 380 .^{\circ}$, um "artigo novo" (AAVV, 2004, p. 624), na secção relativa às garantias dos créditos dos trabalhadores.

\subsection{Confronto com o Direito Comunitário e com a Constituição da República Portuguesa}

Em primeiro lugar, no ponto anterior, perguntámos: o prazo previsto no $\operatorname{art}^{\circ}{ }^{\circ} 2 .^{\circ}, \mathrm{n}^{\circ} 8$ do NRFGS respeita o princípio da equivalência e/ou o princípio da efetividade?

Sendo dois princípios diferentes, temos, metodologicamente, de subdividir a pergunta.

Assim, o prazo do art. ${ }^{\circ} 2^{\circ}$, n. $^{\circ} 8$ do NRFGS é menos favorável do que os prazos relativos a pedidos similares (princípio da equivalência), no caso, outros prazos estabelecidos pelo direito interno relativamente à reclamação de créditos (Domingos, 2009, p. 263)?

Julgamos que o problema não será (tanto) com este princípio.

$\mathrm{J}^{2}$ - Jornal Jurídico | Volume 1 | Número 1 


\section{pontěditora}

Com efeito, pegando nos exemplos já dados pela doutrina (Domingos, 2009, p. 263), o prazo (um ano) será, até, superior, porque o prazo de reclamação de créditos do processo de insolvência é, no máximo, de trinta dias ( $\operatorname{art}^{\circ}{ }^{\circ} 36^{\circ}$, j) do CIRE) e o prazo de reclamação de créditos na execução comum é de quinze dias ( $\operatorname{art}^{\circ} 788 .^{\circ}$, n. $^{\circ} 2$ do CPC).

Já olhando para o prazo que o trabalhador dispõe para reclamar créditos junto da sua entidade patronal, é também um prazo de um ano (art. ${ }^{\circ} 337 .^{\circ}$ do CT), que começa, da mesma forma, a contar a partir do dia seguinte ao da cessação do contrato de trabalho - até aqui há, até, uma equivalência absoluta -, mas com uma diferença essencial, que pode fazer perigar o cumprimento deste princípio: por ser um prazo de prescrição, pode ser interrompido $\left(\operatorname{art}^{\circ}{ }^{\circ} 323 .^{\circ}\right.$ do CC); o do art. $^{\circ} 8 .^{\circ}$, n. $^{\circ} 2$ do NRFGS, sendo de caducidade, não pode (art. $328 .^{\circ}$ do CC). Assim, e como ficou bem demonstrado no Acs. elencados no primeiro grupo, este último prazo pode ser manifestamente menos favorável do que aquele prazo.

É, aliás, essa diferença essencial que tornava o prazo anterior do art. $^{\circ} 319 .^{\circ}$ da $\mathrm{RCT}$ conforme com o Direito Comunitário (Domingos, 2009, pp. 263 e 264) e torna o atual desconforme, se não pelo princípio da equivalência, indubitavelmente, pelo princípio da efetividade.

Pergunta-se, então: o prazo do art. $^{\circ}$ 2. $^{\circ}$, n. $^{\circ} 8$ do NRFGS torna, na prática, impossível o exercício dos direitos reconhecidos pela ordem jurídica comunitária (princípio da efetividade), no caso, o direito dos trabalhadores ao pagamento dos créditos laborais em dívida, em caso de insolvência do empregador, por instituição de garantia?

Sim. Ou, mais rigorosamente, pode tornar.

O pagamento a um trabalhador, pelo FGS, de créditos emergentes do contrato de trabalho ou da sua violação ou cessação depende, nos termos do art. $^{\circ} 1 .^{\circ}$, n. $^{\circ} 1$, alíneas a), b) e c) do NRFGS, da declaração da insolvência do empregador, ou de ser proferido despacho do juiz a designar o AJP, em caso de PER, ou de ser proferido despacho de aceitação do requerimento proferido pelo IAPMEI.

O requerimento do trabalhador a solicitar o pagamento dos créditos laborais ao FGS tem de ser instruído, de acordo com o art. $^{\circ} 5^{\circ}$, n. $^{\circ}$ 2, a) do NRFGS, com declaração comprovativa da natureza e do montante dos créditos em dívida declarados no requerimento pelo trabalhador. Assim, para que o trabalhador possa entregar o seu requerimento devidamente instruído, tem de, por um lado, haver declaração de insolvência ou início do PER ou do procedimento extrajudicial de recuperação de empresas, e, por outro lado, nesses processos, ter havido reclamação de créditos. 


\section{pontěditora}

O processo de insolvência pode ter início por pedido apresentado pelo próprio devedor (art. ${ }^{\circ}$ 18. ${ }^{\circ}$ do CIRE) ou por qualquer credor ou pelo Ministério Público, em representação das entidades cujos interesses lhe estão legalmente confiados (art. ${ }^{\circ} 20 .^{\circ}$ do CIRE).

No caso da apresentação à insolvência por parte do devedor, que deve acontecer dentro dos trinta dias seguintes à data do conhecimento da situação de insolvência (art. ${ }^{\circ} 18 .^{\circ}$, n. $^{\circ} 1$ do CIRE), por esta apresentação implicar o reconhecimento da sua situação de insolvência, a declaração ocorrerá, se cumprido o art. $^{\circ} 28 .^{\circ}$ do CIRE, até ao terceiro dia útil seguinte ao da distribuição da petição inicial ou, existindo vícios corrigíveis, ao do respetivo suprimento.

No caso de a insolvência ser requerida por outros legitimados, os requisitos e a tramitação processual até à declaração da insolvência é mais complexa e demorada:

i) Estes legitimados só podem requerer a insolvência se se verificar a existência de algum dos factos-índice previstos no art. ${ }^{\circ} 20 .^{\circ}$, n. $^{\circ} 1$ do CIRE como, por exemplo, no que diz respeito a créditos laborais, se houver um incumprimento generalizado, nos últimos seis meses, de dívidas emergentes de contrato de trabalho, ou da sua violação ou cessação (art. ${ }^{\text {o }}$ $20 .^{\circ}$, n. $\left.^{\circ} 1, \mathrm{~g}\right)$, iii) do CIRE).

ii) Depois de apresentado o requerimento de declaração de insolvência, se cumprido o art. ${ }^{\circ}$ 29. ${ }^{\circ}$ do CIRE, até ao terceiro dia útil seguinte ao da distribuição da petição inicial, o tribunal manda citar pessoalmente o devedor; pode, ainda, acontecer que, antes de ser determinada a citação do devedor, seja concedido ao requerente prazo para corrigir vícios sanáveis (art. ${ }^{\circ}$ 27. ${ }^{\circ},{ }^{\circ}$ 1, b) do CIRE).

iii) Sendo citado, o devedor tem prazo de dez dias para deduzir oposição (art. ${ }^{\circ} 30 .^{\circ}$, n. $^{\circ} 1$ do CIRE).

iv) Se se opuser, é marcada audiência de discussão e julgamento para, se cumprido o art. ${ }^{\circ}$ $35 .^{\circ}$, n. $^{\circ} 1$ do CIRE, um dos cinco dias subsequentes; e, se não logo, no prazo de cinco dias, é declarada sentença de insolvência ( $\operatorname{art}^{\circ}{ }^{\circ} 35^{\circ}$, n. $^{\circ} 8$ do CIRE).

v) Se não se opuser, a insolvência é declarada, se cumprido o art. ${ }^{\circ} 30 .^{\circ}$, n. $^{\circ} 5$ do CIRE, no dia útil seguinte ao termo do prazo de dez dias que o devedor tinha para deduzir oposição.

Só nesta fase, é fácil concluir como há muitos fatores que o trabalhador não controla, e que a ele são alheios, e que podem, facilmente, influir no esgotamento do prazo para entrega do referido requerimento. Por exemplo:

i) O trabalhador, para requerer a insolvência do seu empregador, só o poderá fazer se se verificar a existência de algum dos factos índices previstos no art. $^{\circ} 20 .^{\circ}$ do CIRE, o que pode 


\section{pontěditora}

significar ter de esperar que as dívidas emergentes de contrato de trabalho, da sua violação ou cessação perfaçam seis meses.

ii) Se ainda não se verificar a existência desses factos índices, só o devedor pode apresentarse à insolvência, tendo da mesma conhecimento (art. ${ }^{\circ} 18 .^{\circ}$, n. $\left.^{\circ} 1\right)$.

iii) $\mathrm{Na}$ fase da citação do devedor várias vicissitudes podem ocorrer (ex vi art. $17 .^{\circ}$ do CIRE), dilatando o período que medeia entre o despacho de citação e a efetivação da citação: não ser possível a entrega da carta da citação por via postal e a carta ficar depositada em estabelecimento postal, até oito dias (art. ${ }^{\circ} 228 .^{\circ}$, n. $^{\circ} 5$, para as pessoas singulares e $\operatorname{art}^{\circ}{ }^{\circ} 246 .^{\circ}$, para as pessoas coletivas, ambos do CPC); não haver levantamento da carta nesse prazo e, em consequência, ser devolvido o expediente; repetição da citação por via postal, no caso de pessoa coletiva, com possibilidade de se verificar, novamente, a não assinatura do aviso de receção, em que a citação se considera efetuada no oitavo dia posterior à data em que foi deixado o aviso (arts. 246..$^{\circ}$ e 230. ${ }^{\circ}$, n. ${ }^{\circ} 2$ do CPC); recurso à citação por agente de execução ou por mandatário judicial, em que o citando não seja encontrado de imediato, ou nem sequer seja encontrado (arts. 231. $.^{\circ}, 237 .^{\circ}, 238 .^{\circ}$ e $246 .^{\circ}$, todos do CPC); o citando se encontrar em parte incerta, em que se recorrerá à citação edital (arts. $236 .^{\circ}, 240 .^{\circ}$ e $241 .^{\circ}$, todos do CPC). É certo que pode ser dispensada a audiência do devedor, nos termos do art. ${ }^{\circ} 12 .^{\circ}$ do CIRE, mas tal só é possível se a audiência acarretar demora excessiva, pelo facto do devedor residir no estrangeiro ou ser desconhecido o seu paradeiro.

iv) Efetuada a citação, o devedor pode opor-se à insolvência até ao terceiro dia útil subsequente ao termo do prazo ( $\operatorname{art}^{\circ}{ }^{139 .^{\circ}}$, n. ${ }^{\circ} 5$ do CPC, ex vi art. $^{\circ} 17 .^{\circ}$ do CIRE).

v) E, se houver oposição, pode haver audiência de discussão e julgamento.

E não é à toa que se disse, várias vezes, se cumprido o previsto em $x$ artigo. Como é do conhecimento geral, o volume de processos nos tribunais faz com que, na maior parte dos casos, seja impossível cumprir os prazos previstos na lei. Fora que, na prática, há ainda que ter em conta que os atos do tribunal são antecedidos pelas conclusões eletrónicas, e que estas não ocorrem logo, em alguns tribunais, ocorrem, até, só uma vez por semana.

Deste modo, mesmo que se esteja perante um trabalhador diligente, que toma a iniciativa de dar início ao processo de insolvência da sua entidade patronal, até à declaração da insolvência, por causa do que referimos, pode, desde a cessação do seu contrato de trabalho, já se ter volvido vários meses, possivelmente, mais de seis meses.

Além disso, como o requerimento para pagamento de créditos laborais pelo FGS tem de ser instruído com declaração ou cópia autenticada de documento comprovativo dos créditos 


\section{pontěditora}

reclamados pelo trabalhador, emitida pelo AI, há que ter, ainda, em conta a fase da verificação de créditos no processo de insolvência.

Esta fase inicia-se com a reclamação de créditos. Um credor tem o prazo designado na sentença para apresentar a sua reclamação de créditos, que pode ir até trinta dias (arts. 128. ${ }^{\circ},{ }^{\circ} .^{\circ} 1$ e $36 .^{\circ}$, n. ${ }^{\circ} 1, \mathrm{j}$ ), ambos do CIRE) após a notificação ou citação (com éditos de cinco dias, no caso de publicação no portal Citius) da sentença de declaração da insolvência (art. ${ }^{\circ} 37 .^{\circ}$ do CIRE). Ou seja, há que, desde logo, contar com, por regra, mais de um mês.

Depois do termo do prazo das reclamações, o AI tem quinze dias para elaborar a relação de créditos reconhecidos e não reconhecidos ( $\operatorname{art}^{\circ}{ }^{\circ} 129 .^{\circ}$, n. $^{\circ} 1$ do CIRE).

Só após a elaboração dessa relação está o AI em posse dos dados necessários para poder emitir a referida declaração, porque só aí pode atestar que o crédito foi reclamado e em que termos o foi. Ou seja, pelo menos, temos mais quinze dias, a que acresce o tempo que o AI demorar a emitir a respetiva documentação.

Contudo, pode o Administrador não reconhecer como devido o crédito do trabalhador (art. ${ }^{\circ}$ 129. ${ }^{\circ}$, n. 3 do CIRE) e, por isso, não emitir a referida declaração. Segue-se, então, a impugnação da lista, no prazo de dez dias (art. $130 .^{\circ}$, n. $^{\circ} 1$ do CIRE), com possível resposta, também no prazo de dez dias, do AI e qualquer interessado que assuma posição contrária, incluindo o devedor (art. ${ }^{\circ} 131 .^{\circ}$, n. $^{\circ} 1$ e n..$^{\circ} 3$ ), e se a houver (art. ${ }^{\circ} 131 .^{\circ}$, n. $^{\circ} 3$ do CIRE), temos, ainda, a emissão de parecer da comissão de credores, dentro dos dez dias posteriores ao termo do prazo das respostas às impugnações ( art. $^{\circ} 135 .^{\circ}$ do CIRE), a possibilidade de existir tentativa de conciliação ( art. $^{\circ} 136 .^{\circ}$ do CIRE) e a audiência de julgamento (arts. $138 .^{\circ}$ e $139 .^{\circ}$ do CIRE). Só perante uma sentença favorável ao trabalhador emitirá o AI a tal declaração comprovativa dos créditos reclamados. Se a sentença não for favorável, o trabalhador pode ainda recorrer para a $2 .^{\text {a }}$ instância ( art. $^{\circ} 14 .^{\circ}$ ) e, ainda mais, terá de aguardar.

A esta delonga poder-se-ia contrapor que a única declaração que o AI tem de emitir é a comprovar que reclamou créditos e não que houve o seu reconhecimento. Recordamos, aliás, que um argumento deste tipo foi usado no Ac. n. ${ }^{\circ}$ 3, acima referenciado, para defender a intempestividade do exercício do direito do trabalhador.

Contudo, caso o Administrador se recusasse a emitir a referida declaração, restar-lhe-ia recorrer, nos termos do art. ${ }^{\circ} 5^{\circ}$, n. $^{\circ}$ 2, alínea c) do NRFGS, à Autoridade para as Condições do Trabalho. No entanto, diz, pelo menos, a nossa experiência que a atuação desta entidade não é tão célere quanto desejável. Além do que, para ser suscitada a sua intervenção, tem de haver 


\section{pontěditora}

recusa por parte do AI, o que implica que se tem de passar por parte da tramitação acima indicada. Ou seja, mais uns dias se passaram, entretanto.

Admitimos, ainda, que se possa solicitar a emissão, por parte do AI, da tal declaração, após a elaboração da lista provisória de credores do art. ${ }^{\circ} 154 .^{\circ}$ do CIRE. O problema é que, se o AI juntar essa lista pelo menos oito dias antes da assembleia de apreciação do relatório (art. ${ }^{\circ} 155$. $^{\circ}$, n. ${ }^{\circ} 3$ do CIRE), os credores podem não conseguir integrar esta lista, por ainda não se ter findado o prazo da reclamação de créditos.

De qualquer dos modos, reiteramos, com esta fase perde-se sempre mais de 1 mês, a que acresce o tempo que o AI demorar a emitir a respetiva documentação.

E outras sub-hipóteses se poderiam suscitar - e que, para que não se torne demasiado fastidioso, nos limitamos a elencar - como os créditos do trabalhador serem reclamados após terminar o prazo para a reclamação de créditos, através da verificação ulterior de créditos (art. ${ }^{\circ} 146 .^{\circ}$ do CIRE), como aconteceu no Ac. n. ${ }^{\circ}$ 3, em que o trabalhador esteve um ano e três meses à espera da sentença para reconhecimento do seu créditos, ou a sentença de declaração de insolvência ser proferida de acordo com o art. ${ }^{\circ} 39 .^{\circ}$ do CIRE, por insuficiência da massa insolvente, sem ser designado prazo para a reclamação de créditos, o que obrigaria ao pedido de complemento de sentença (art. ${ }^{\circ} 39 .^{\circ}$, n. $^{\circ} 1$, n. $^{\circ} 2$, al. a), n. ${ }^{\circ} 3$ e n. ${ }^{\circ} 4$ do CIRE).

E o mesmo problema pode acontecer no PER.

Desde logo, só o devedor tem legitimidade processual para dar início a esse procedimento (art. ${ }^{\circ}$ 17. ${ }^{\circ}-\mathrm{C}$, n. $^{\circ}$ s 1,2 e n. ${ }^{\circ} 3$, a) do CIRE).

Portanto, o trabalhador-credor não tem qualquer controlo relativamente ao início deste processo.

Depois do devedor dar início ao processo, o juiz deve nomear, se cumprido o art. ${ }^{\circ} 17 .^{\circ}-\mathrm{C}$, n. $^{\circ} 4$ do CIRE (anterior n. ${ }^{\circ}$ 3, al. a)), de imediato, por despacho, AJP.

Este despacho será, depois, publicado no portal Citius, e, a partir daí correrá o prazo de vinte dias para os credores reclamarem os seus créditos (art. ${ }^{\circ} 17^{\circ}-\mathrm{D}, \mathrm{n}^{\circ}{ }^{2}$ ) do CIRE).

Se cumprido o art. $^{\circ} 17 .^{\circ}-\mathrm{D}$, n. $^{\circ} 2,2 .^{\mathrm{a}}$ parte do CIRE, no prazo de cinco dias após o termo do prazo da reclamação de créditos, o AJP elabora uma lista provisória de créditos.

Contudo, essa lista pode ser impugnada no prazo de cinco dias úteis, dispondo o juiz, em seguida, se cumprido o art. ${ }^{\circ} 17 .^{\circ}-\mathrm{D}$, n. $^{\circ} 3$ do CIRE, de idêntico prazo para decidir sobre as impugnações formuladas. 


\section{pontěditora}

Após a lista provisória de créditos, ou a decisão sobre as impugnações, está o AJP habilitado a emitir a documentação necessária para o trabalhador requerer o pagamento dos créditos laborais ao FGS.

Ora, só contando desde a publicação do despacho de nomeação do AJP, medeia, pelo menos, um mês.

A que acresce o tempo que o AJP necessita para emitir a documentação, sem olvidar que, na prática, não é raro o incumprimento dos prazos legais de nomeação do AJP, da junção da lista provisória de créditos, e da decisão sobre as impugnações.

Em suma, como pensamos que ficou amplamente exemplificado, é uma possibilidade real que o trabalhador, por fatores a que é totalmente alheio, não possa entregar o requerimento para pagamento dos créditos laborais pelo FGS, dentro do prazo de um ano a partir do dia seguinte àquele em que cessou o seu contrato de trabalho.

Aliás, pelas perguntas feitas ao TJ, pelo TAF de Viseu, em sede de reenvio prejudicial, a que aludimos acima, depreendemos que terá sido esta realidade que terá motivado o pedido prejudicial.

Mas, e o entendimento vertido pela primeira das duas teses que referimos não resolve o problema?

Esse entendimento, por muito que possa resolver vários casos "apanhados" na transição de um regime para outro - o que, pelo menos, se saúda - não resolve outros tantos:

a) Quando os contratos de trabalho cessaram antes da data da entrada em vigor do NRFGS e o requerimento tenha sido apresentado após 4 de maio de 2016; e

b) Relativamente aos contratos de trabalho que cessaram após a data da entrada em vigor do NRFGS, em que os trabalhadores, por motivos a si alheios, conforme ilustrámos, se viram impedidos de cumprir o prazo do $\operatorname{art}^{\circ}{ }^{2} .^{\circ}$, n. $^{\circ} 8$ do NRFGS.

A questão essencial mantém-se, portanto, por resolver. Essa tese responde, somente, tendo por base normas sobre alteração de prazos, quando a discordância aqui expressa é mais profunda, por ser relativa à validade e à interpretação da própria norma que altera o prazo.

Consequentemente, na sequência do afirmado pelo TJ, e ao abrigo do art. ${ }^{\circ} 8 .^{\circ}$, n. $^{\circ} 4$ da CRP (Canotilho e Moreira, 2014, 271), dado que o art. $^{\circ}$ 2. $^{\circ}$, n..$^{\circ} 8$ do NRFGS não está em conformidade com as exigências do Direito Comunitário, no caso, pelo menos, indubitavelmente, quanto ao princípio da efetividade, e se se entender que nenhuma interpretação conforme com o Direito Comunitário é possível, deve, então, ser recusada a sua aplicação ou podem os tribunais pedir ao TJ, ao abrigo do art. $^{\circ} 267 .^{\circ}$ do Tratado sobre o 


\section{pontěditora}

Funcionamento da União Europeia que se pronuncie sobre o correto entendimento ou a validade desta disposição, em sede de reenvio prejudicial.

Por isso, não podemos concordar com os Acs. do segundo grupo - a interpretação dada não é conforme a Diretiva 2008/94/CE, nem com a jurisprudência comunitária (aliás, a citada pelo Ac. n. $^{\circ} 2$ não tem a ver com esta questão) e não é respeitada a finalidade social daquela.

Por outro lado, julgamos que a norma está, igualmente, ferida de inconstitucionalidade, por violação material do art. $^{\circ} 59 .^{\circ}$, n. $^{\circ} 2$ e n..$^{\circ} 3$ da CRP.

Voltando à contextualização feita, nos termos do art. ${ }^{\circ} 59 .^{\circ}$, n. $^{\circ} 2$ da CRP, o Estado tem a expressa incumbência constitucional de assegurar a retribuição a que os trabalhadores têm direito, e nos termos do n. ${ }^{\circ} 3$, é constitucionalmente consagrado que os salários gozam de garantias especiais. Prevendo a lei ordinária um prazo que impossibilita, na prática, a um trabalhador de beneficiar da garantia especial de ver os seus créditos salariais pagos pelo FGS, tal significa que o Estado se frustou à referida incumbência constitucional de assegurar o pagamento da retribuição, e, igualmente, que o salário não beneficiou de garantia especial.

\section{Conclusão}

A redação do art. $^{\circ} 2 .^{\circ}$, n. $^{\circ} 8$ do NRFGS tem dois problemas: o prazo para requerer o pagamento ao FGS deixou de estar indexado ao prazo de prescrição dos créditos laborais e, por isso, deixou de aproveitar as causas de interrupção da prescrição, e o legislador manteve, como data relevante para o início da contagem, a data da cessação do contrato de trabalho.

Problemas que o legislador deve resolver, por forma a respeitar a Diretiva 2008/94/CE e a nossa Constituição. Como?

Alvitramos três hipóteses:

1) Voltar à redação anterior;

2) Manter a redação atual, mas prever casos de interrupção e suspensão para o prazo, o que, mesmo sendo este de caducidade, é permitido pela parte final do $\operatorname{art}^{\circ} 328 .^{\circ}$ do $\mathrm{CC}$;

3) Estipular um prazo, por exemplo, de trinta dias desde o reconhecimento do crédito no processo de insolvência, PER ou procedimento extrajudicial de recuperação.

Sugerimos, por último, na senda do aconteceu por causa do FGS ter indeferido o pagamento de créditos laborais reclamados no âmbito do PER (Abrantes, 2015, 411), e atentos os interesses que estão em causa, a reapreciação oficiosa, ou, pelo menos, a concessão de um prazo para requerer a reanálise da decisão, dos requerimentos que deram entrada após a entrada em vigor 


\section{pontěditora}

do NRFGS e que foram indeferidos, somente, pelo facto do pagamento não ter sido requerido a partir do dia seguinte àquele em que cessou o contrato de trabalho.

P.S.: Após termos submetido este artigo, a 31 de maio, foi publicado o Ac. do Tribunal Constitucional n. $328 / 2018$, de 27 de junho (disponível em www.tribunalconstitucional.pt) que, em sede de fiscalização concreta, decidiu "julgar inconstitucional a norma contida no artigo $2 .^{\circ}$, n. $^{\circ} 8$, do Decreto-Lei n. ${ }^{\circ}$ 59/2015, de 21 de abril, na interpretação segundo a qual o prazo de um ano para requerer o pagamento dos créditos laborais, certificados com a declaração de insolvência, cominado naquele preceito legal é de caducidade e insuscetível de qualquer interrupção ou suspensão".

Da argumentação expendida, permitimo-nos destacar o seguinte trecho: "Não é inócua a apontada ligação entre o mecanismo do FGS e a norma do n. ${ }^{\circ} 3$ do artigo 59..$^{\circ}$ da CRP. Tratando-se de uma das garantias ali previstas, ao escolher (apesar de, nessa escolha, se encontrar vinculado pelo Direito da Uniãol instituir o FGS como uma das garantias especiais da retribuição, o legislador está vinculado à construção de um regime que lhe assegure um mínimo de efetividade, sem a qual resultaria esvaziada de sentido a norma constitucional, com respeito pela igualdade (artigos $13 .^{\circ} \mathrm{e}$ $59 .^{\circ}$, n. ${ }^{\circ} 1$, da CRP). Por outro lado, tratando-se de atribuir, no apontado contexto, um direito a uma prestação pecuniária, e de limitar no tempo a efectividade desse direito pelo não exercício, tal atribuição deve operar, na compaginação destas duas vertentes, segundo regras claras, certas e objetivas exigência decorrente do princípio do Estado de direito democrático (artigo $2 .^{\circ}$ da Constituição) .

Tendo presentes as linhas essenciais do NRFGS (...) verificam-se aporias que o afastam do padrão de efetividade e certeza acabado de traçar."

\section{Referências}

- AAVV (2004). Código do Trabalho - Anotado (3. a edição). Coimbra: Almedina. 


\section{pontěditora}

- Abrantes, José João (2015). O Fundo de Garantia Salarial nos processos de insolvência e de revitalização. In Catarina Serra (Ed.), III Congresso de Direito da Insolvência (pp. 409 - 412). Coimbra: Almedina.

- Amado, João Leal Amado (1994). A Proteção do Salário. Boletim da Faculdade de Direito da Universidade de Coimbra - Suplemento vol. XXXIX, pp. 1 - 260.

- Canotilho, J.J. Gomes \& Moreira, Vital (2014). Constituição da República Portuguesa: anotada-artigos $1 .^{\circ}$ a $107 .^{\circ}$ (4. ${ }^{\text {a }}$ edição revista). Coimbra: Coimbra Editora.

- Costeira, Joana (2017). Os Efeitos da Declaração de Insolvência no Contrato de Trabalho: A Tutela dos Créditos Laborais (2. edição). Coimbra: Almedina.

- Domingos, Maria Adelaide (2009). A tutela dos créditos laborais através do Fundo de Garantia Salarial. In António Moreira (Ed.), XI-XII Congresso Nacional de Direito do Trabalho (pp. 249 - 270). Coimbra: Almedina.

- Justo, A. Santos (2012). Introdução ao Estudo do Direito (6. ${ }^{\mathrm{a}}$ edição). Coimbra: Coimbra Editora.

- Monteiro, Leonor Pizarro (2016). O Trabalhador e a Insolvência da Entidade Empregadora. Coimbra: Almedina.

- Pires, Miguel Lucas (2015). Dos Privilégios Creditórios (2. ${ }^{a}$ edição). Coimbra: Almedina.

- Serra, Catarina (2017). PER, PROCESSOS E CRÉDITOS LABORAIS - Uma análise tridimensional (jurisprudência, novíssimo Direito da Insolvência e projectado Direito Europeu. Prontuário de Direito do Trabalho, 2017 - II, pp. 159 
